\title{
COSEISMIC DEFORMATION AND SEISMIC FAULT OF THE 17 NOVEMBER 2015 M=6.5 EARTHQUAKE, LEFKADA ISLAND
}

\author{
Ganas Ath. ${ }^{1}$, Briole P. ${ }^{3}$, Melgar D. ${ }^{3}$, Bozionelos G. ${ }^{4}$, Valkaniotis S. ${ }^{5}$, Avallone \\ A. ${ }^{6}$, Papathanassiou G. ${ }^{7}$, Mendonidis E. ${ }^{1}$ and Elias P. ${ }^{1}$ \\ INational Observatory of Athens,aganas@noa.gr \\ ${ }^{2}$ Ecole Normale Supérieure, Paris, France, briole@ens.fr \\ ${ }^{3}$ University of California, Berkeley Seismological Laboratory dmelgar@berkeley.edu \\ ${ }^{4}$ National and Kapodistrian University of Athens, georgebozionelos@gmail.com \\ ${ }^{5}$ Koronidos Str., 42100 Trikala, Greece, valkaniotis@yahoo.com \\ ${ }^{6}$ INGV, Via di Vigna Murata, 60500143 Roma Italy, antonio.avallone@ingv.it \\ ${ }^{7}$ Aristotle University of Thessaloniki, gpapatha@geo.auth.gr
}

\begin{abstract}
On November 17, 2015 a strong, shallow earthquake, Mw 6.5, occurred on the island of Lefkada along a strike-slip fault with right-lateral sense of slip. The event triggered widespread environmental effects that were mainly reported at the south and western part of the island while moving towards the eastern part, the intensity and severity of these earthquake-induced deformations were decreased. Relocation of seismicity and inversion of geodetic data suggests that the seismic fault runs parallel to the west coast of Lefkada, along the Aegean - Apulia plate boundary. The earthquake measured Mw=6.5 using the PGD relation of Melgar et al (2015, GRL). The fault plane strikes $N 20 \pm 5^{\circ} \mathrm{E}$ and dips to east with an angle of about $70 \pm 5$ degrees. Coseismic deformation was measured in the order of tens of centimeters of horizontal motion by continuous GPS stations of NOANET (the NOA GPS network) and by InSAR (Sentinel 1A image pairs). Released interferograms from various groups show a large decorrelation area that extends almost along all the western coast of Lefkada, observation which provides strong support of landsliding. A coseismic slip model was produced from inversion of the ascending InSAR. We have not observed significant vertical motion of the shoreline and this is consistent with the predictions of the model. Keywords: Greece, Satellite, GPS, Lefkada.
\end{abstract}

\section{Tectonic setting}

Lefkada (Ionian Sea, Greece) is considered as among the most active tectonic areas in Europe and one of the most active zones in the eastern Mediterranean region. Lefkada has been repeatedly subjected to strong ground shaking due to the proximity of the island to $140-\mathrm{km}$ long CTF (Cephalonia Transform Fault; Fig. 1, Louvari et al., 1999; Sachpazi et al., 2000). The most recent strong earthquake, with magnitude of Mw 6.2, occurred on August 14, 2003 offshore the western coast of Lefkada Island, causing severe damages around the whole island (Papadopoulos et al., 2003; Karakostas et al. 2004; Papathanassiou et al., 2005). Pavlides et al. (2004) assumed a division of 
40-km long Lefkada segment of CTF into two smaller segments separated by Sesoula Islet westward of Lefkada, striking at NNE-SSW to NE-SW and behaving rather independently in terms of seismic reactivation. The northern limit of Lefkada segment of CTF is constrained by a thrust solution of the November 4, 1973 earthquake with $\mathrm{M}=5.8$ (Baker et al., 1997), offshore the northwest coast of Lefkada island.

In terms of surface geology, Lefkada is built with sedimentary rocks (mainly carbonates) that belong to the so-called external Hellenides (Jacobshagen, 1979). In particular, the boundary between the two different geological zones - Ionian and Paxos, runs through this region and outcrops onshore Lefkada Island, forming the noteworthy Ionian Thrust. The main part of the island is consisted of a carbonate sequence of the Ionian zone, while the SW part of the island consists of limestone of Paxos geological zone (Bornovas, 1964). Detailed field observations on South Lefkada (Cushing M, 1985; Lekkas et al., 2001; Rondoyanni et al., 2012), showed several active and neotectonic faults striking N-S and NE-SW, of which the most important can be considered the Athani fault. This is a NNESSW-striking fault, very well expressed in the region's morphology and marked on satellite images and aerial photos.

\section{The 17 November 2015 earthquake}

On November 17, 2015, 07:10 GMT (09:10 local time) central Ionian Sea was struck by a strong, shallow earthquake (NOA magnitudes ML6.0-Mw 6.4 respectively; depth $11 \mathrm{~km}$ ). Based on published Moment Tensor solutions this earthquake occurred on a near-vertical strike-slip fault running along Lefkada's western coast, with dextral sense of motion in response to ENE-WSW horizontal strain in central Ionian Sea (Ganas et al., 2013). The earthquake ruptured a coastal fault, in contrast to the 2014 events that occurred on dextral strike-slip faults on shore Cephalonia (Valkaniotis et al., 2014; Boncori et al., 2015). 1038 revised NOA aftershock solutions from the period November. 17-December 17, 2015 are plotted in Figure 2. It is evident a general N-S arrangement of aftershocks with two main clusters: one in central Lefkada (Northern cluster) with shallower hypocentres and one in offshore area between Lefkada - Cephalonia (southern cluster). The clusters are possibly formed by Coulomb stress changes on either end of the rupture. Following the earthquake released interferograms from various groups show a large decorrelation area that extends almost along all the western coast of Lefkada, which is known for the existence of numerous landslides (Papathanassiou et al., 2013). This InSAR observation provides strong evidence of landsliding, rock falls etc. We also found extensive landslides during field work and no surface ruptures.

\section{Satellite Geodesy Data}

The National Observatory of Athens during the last 10 years has established several permanent GPS stations in central and western Greece in order to monitor the tectonic motion (Ganas et al., 2008, 2011). In western Greece there are six stations that operate since early 2006 - mid 2007 (VLSM, RLSO, PONT, SPAN, KASI, KIPO; see www.gein.noa.gr/gps.html for network map and site logs). Ganas et al. (2013) presented results showing N-S crustal shortening onshore Lefkada Island of the order of 2-3 mm/yr, which the authors evaluated as "is probably related to increased locking on the offshore Lefkada fault" implying pre-seismic deformation. This paper presents results from data provided by two (2) permanent GPS stations onshore Lefkada (SPAN and PONT) and one station in Cephalonia (VLSM). Our results include: time series of 1-s positions for stations SPAN, PONT (Figure 2) and static offset estimates (Table 1) due to seismic motion of Nov. 17. 2015 event. 


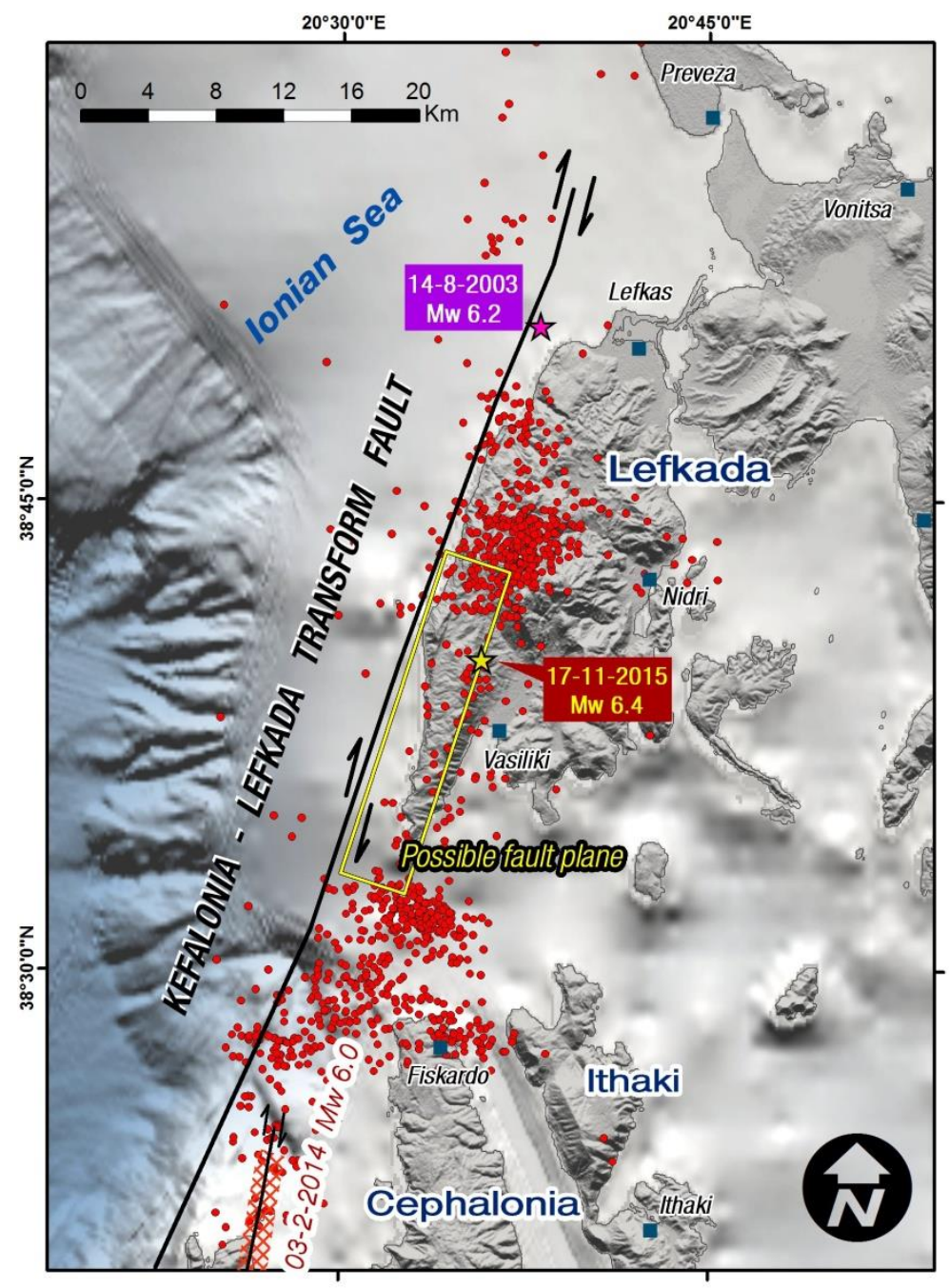

Figure 1 - The 17th November 2015 Lefkada earthquake (yellow star) and aftershock epicentres recorded by National Observatory of Athens (NOA) until Dec. 17, 2015. Dextral faults along the Cephalonia-Lefkada Transform boundary are shown as black lines. The seismic fault is shown by the yellow rectangle (surface projection).

Table 1 - List of NOANET stations with measured co-seismic offsets due to seismic motion. Station info can be seen at www.gein.noa.gr/gps.html.

\begin{tabular}{|c|c|c|c|}
\hline Station & $\mathbf{d E} \mathbf{( m m})$ & $\mathbf{d N}(\mathbf{m m})$ & $\mathbf{d U P}(\mathbf{m m})$ \\
\hline PONT & -201 & -365 & -65 \\
\hline SPAN & -59 & -45 & -3 \\
\hline VLSM & -4 & -12 & -4 \\
\hline
\end{tabular}




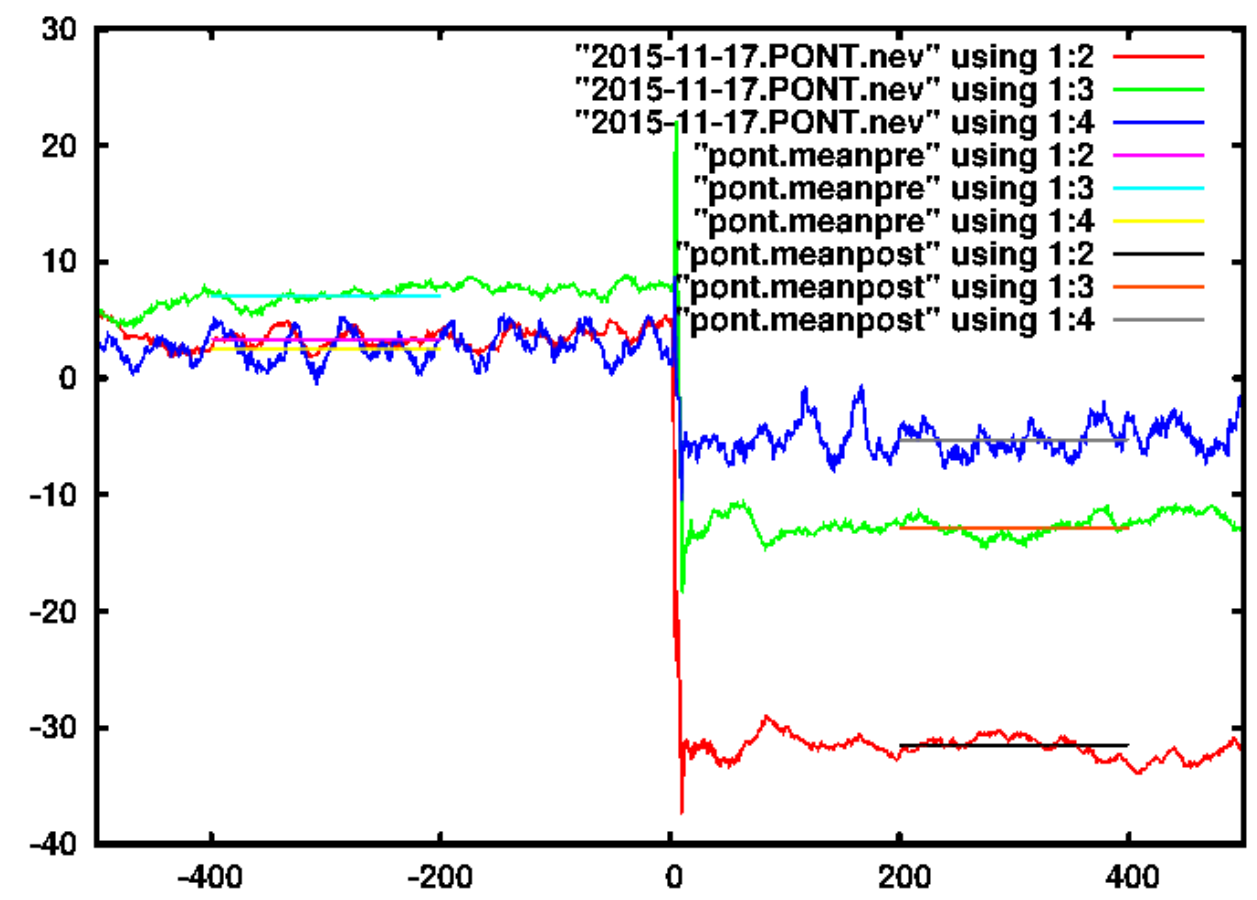

Figure 2 - Graph showing static offsets of NOA station PONT (South Lefkada). Each time series shows the time window in which the average position (and the relative standard deviation) before and after the event have been computed. $\mathrm{X}$-axis is time (s), $\mathrm{Y}$-axis is displacement $(\mathbf{c m})$.

The PGD magnitude of this event (as defined in Melgar et al., 2015; Figure 3) equals to Mw=6.5 a nd it works exceedingly well in this case thanks to the proximity of the permanent GPS stations to the epicentre. First estimate is at only 5 s after origin time. The measurement stabilizes after 20 -s. N eglecting data from the vertical components provides a more stable solution, however both solution $\mathrm{s}$ are quite good.

A preliminary modellling of the co-seismic displacements at the NOA stations VLSM (Cephalonia), PONT and SPAN (Lefkada) together with LOS displacements from SAR interferometry (Sentinel 1A image pair) gives the following parameters for the fault, listed in Table 2. The main differences/improvements (constrained by InSAR) are: a) azimuth $\mathrm{N} 18^{\circ} \mathrm{E}$ instead of $\mathrm{N} 25^{\circ} \mathrm{E}$, and thus more consistent with the Aug. 14, $2003 \mathrm{M}=6.2$ event b) this was very shallow event, this is a consequence of the high value of the GPS offset at PONT (further confirmed by the large number of fringes).

The seismic moment from this geodetic model is $9.07 \times 1018 \mathrm{Nm}$ (intermediate between CMT and GEOSCOPE) but double that of NOA $(4.4 \times 1018 \mathrm{Nm})$. The Sentinel-1A fringe pattern provided by ESA (Michael Foumelis), HUA (I. Parcharidis) and BEYOND (H. Kontoes; http://beyondeocenter.eu/) teams is, at the first order, compatible with this fault model. The fault is very close to the west shore of Lefkada. 


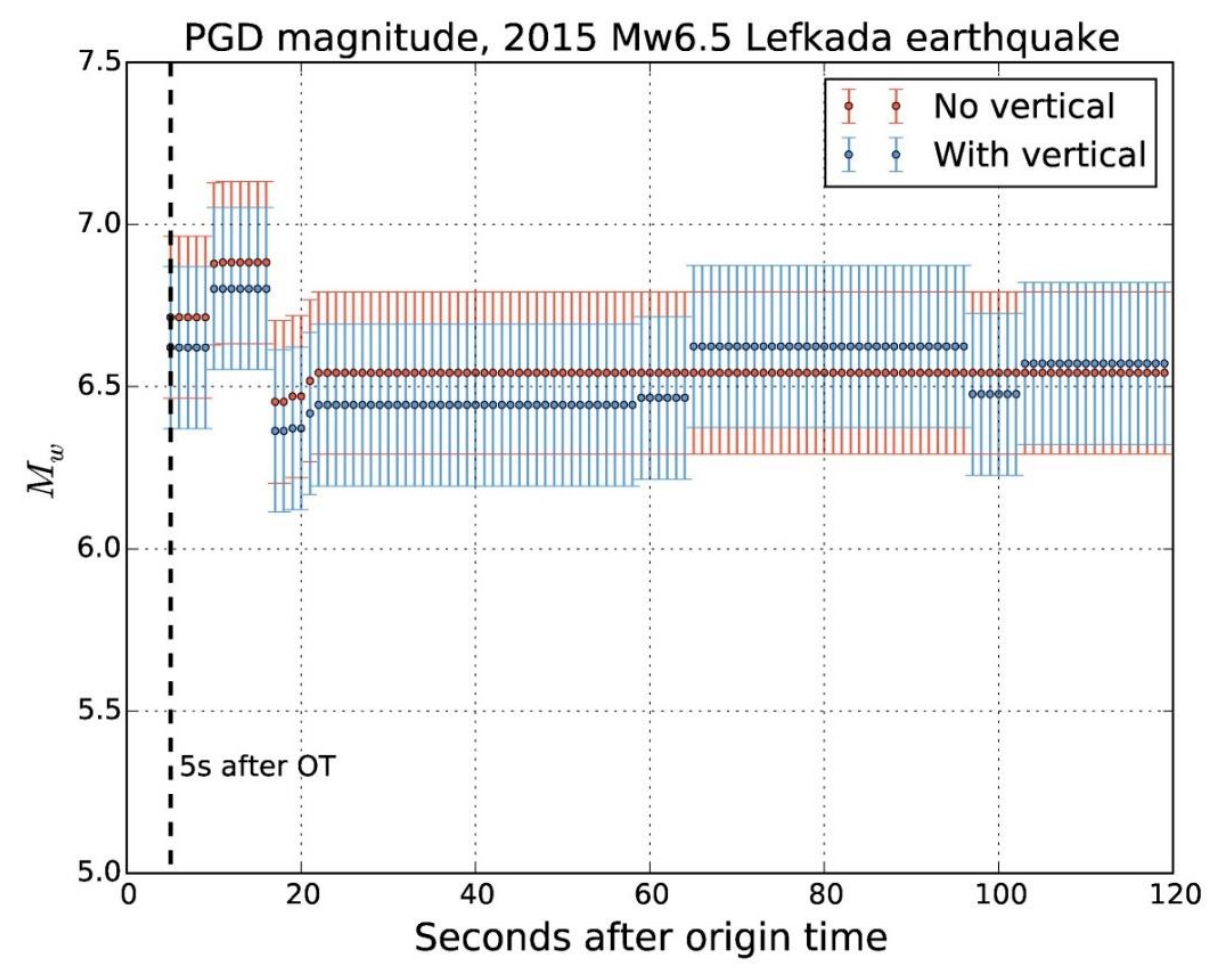

Figure 3 - Plot showing the estimated moment magnitude (Mw=6.5) from the high-rate GPS as a function of time with uncertainties.

Table 2 - Parameters of the seismic fault determined from inversion of geodetic data.

\begin{tabular}{|c|c|}
\hline Seismic Fault Parameter & Value \\
\hline Fault length (km) & 21 \\
\hline Fault width (km) & 10 \\
\hline Fault Dip angle (degrees) & 73 \\
\hline Azimuth (clockwise from North - degrees) & 18 \\
\hline Fault Slip (m) & 1.44 \\
\hline Centre of upper edge of the fault (UTM East, North) & 458000,4271600 \\
\hline Top of the fault (m) & 150 \\
\hline
\end{tabular}

A coseismic slip model was produced from the ascending InSAR (Sentinel 1A image pair; Figure 4), which it's cleaner than the GPS only and both data sets have $\sim 90 \%$ variance reduction. A hostin $\mathrm{g}$ fault plane of $\mathrm{N} 20^{\circ} \mathrm{E}$ and dip-angle of $65^{\circ}$ was used. The inversion shows that highest slip occurr ed to the south of the epicentre and near the surface (depths 0-5 km; Figure 4). The highest amount of slip reached $2.0 \mathrm{~m}$ about $15 \mathrm{~km}$ south of the epicentre. The relocated aftershocks are distributed around the high-slip areas. 


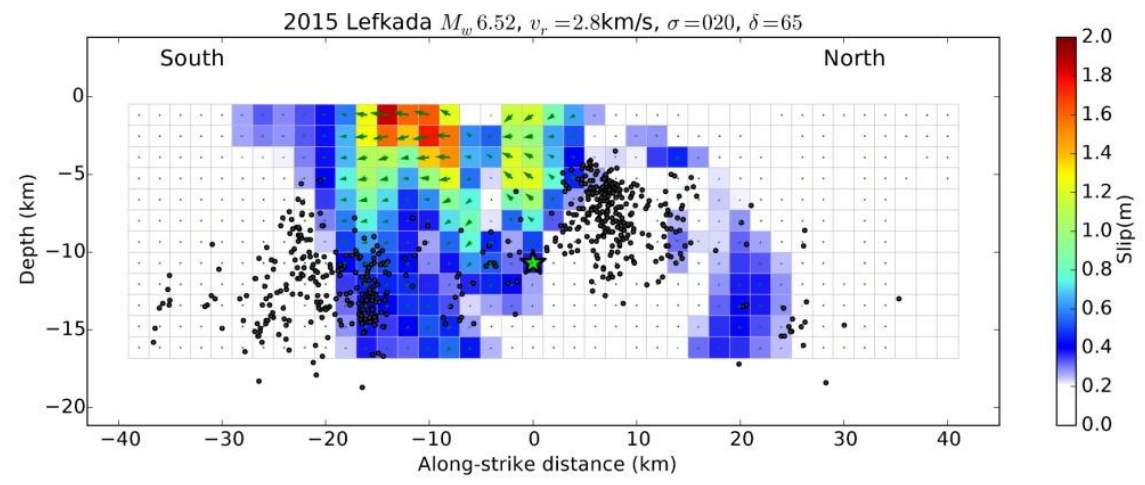

Figure 4 - Along strike view of co-seismic slip distribution (preliminary model). Black dots are relocated aftershocks.

According to the model obtained with the GPS vectors, the maximum land subsidence is $60 \mathrm{~mm}$ in the Vassiliki harbor. Along the west coast of Lefkada the expected vertical displacement ranges be tween -30 and $+16 \mathrm{~mm}$, and the northern coast of Cephalonia, near the southern end of the fault mi ght have been uplifted by $10 \mathrm{~cm}$ according to the model (constrained by the InSAR fringes observe $\mathrm{d}$ in Cephalonia).

\section{Discussion - Conclusions}

The main conclusions are:

a) On 17th November 2015 a shallow Mw=6.5 event occurred along a strike-slip fault with right-lateral sense of slip. Relocation of seismicity and inversion of geodetic data suggests that the seismic fault runs parallel to the west coast of Lefkada, along the Aegean - Apulia plate boundary.

b) The inversion of geodetic data suggests that the upper part of the fault is offshore very close to the coast, and at very shallow depth $(0.5 \pm 0.5 \mathrm{~km})$, as constrained by the azimuth and amplitude of the ground motion at NOA GPS stations and InSAR Sentinel 1A observations (ascending orbit). The fault plane strikes $\mathrm{N} 20 \pm 5^{\circ} \mathrm{E}$ and dips to east with an angle of about $70 \pm 5$ degrees.

c) Environmental effects include liquefaction, extensive rock falls and landslides. No surface ruptures were found in the field. Road cracks are interpreted as secondary phenomena of gravitational nature induced by ground shaking.

d) We have not observed significant vertical motion of the shoreline and this is consistent with the predictions of the model.

\section{Acknowledgments}

We thank the NOA seismic data analysis team for phase data and the BEYOND / HUA / INGV / JPL satellite data analysis teams for Sentinel 1A interferograms. We thank the ESA Seismic Pilot Lead Philippe Bally and the GEO Supersite Coordinator Stefano Salvi, for activating satellite acquisition imagery. We are indebted to local residents Gerassimos Katopodis and Panagiotos Zogos for their help in the field. We also thank Efthimios Lekkas, Iannis Koukouvelas, Efthimios Sokos, Yiannis Kassaras, Vassilis Karakostas, Panagiotis Paschos, Alexandra Moshou, Panagiotis Argyrakis, Fillippos Doukatas and Spiros Pavlides for discussions. Fieldwork was funded by the GSRT project INDES-MUSA http://www.indes-musa.gr/. The establishment of NOANET in the Ionian Islands was funded by EU projects PREVIEW (FP6 contract 516172; scientific responsible A. Ganas), TERRAFIRMA 
(scientific responsible A. Ganas) RASOR (FP7-SPACE-2013-1 contract 606888; scientific responsible A. Ganas) and the GSRT project ODISSEUS (scientific responsible G. Drakatos).

\section{References}

Baker, C., Hatzfeld, D., Lyon-Caen, H., Papadimitriou, E. and Rigo, A., 1997. Earthquake mechanisms of the Adriatic Sea and Western Greece: implications for the oceanic subduction-continental collision transition, Geophysical Journal International, 131, 559594.

Boncori, M.J.P., Papoutsis, I., Pezzo, G., Tolomei, C., Atzori, S., Ganas, A., Karastathis, V., Salvi, S., Kontoes, C. and Antonioli, A., 2015, The February 2014 Cephalonia Earthquake (Greece): 3D Deformation Field and Source Modeling from Multiple SAR Techniques, Seismological Research Letters, January/February 2015, 86(1), 124-137. http://dx.doi.org/10.1785/0220140126.

Bornovas, J., 1964. Géologie de l'île de Lefkade, Geol. Geophys. Res., Special Publication by Greek Geological Survey, 10(1). Athens.

Cushing, M., 1985. Evolution structurale de la marge nord ouest helle'nique dans l'1^le de Levkas et ses environs (Gre`ce nord occidentale). The`se 3me cycle, Univ. de Paris-Sud.

Ganas, A., Drakatos, G., Rontogianni, S., Tsimi, C., Petrou, P., Papanikolaou, M., Argyrakis, P., Boukouras, K., Melis, N. and Stavrakakis, G., 2008. NOANET: the new permanent GPS network for Geodynamics in Greece, Geophysical Research Abstracts, Vol. 10, EGU2008-A04380.

Ganas, A., Chousianitis, K., Drakatos, G., Papanikolaou, M., Argyrakis, P., Kolligri, M., Petrou, P., Batsi, E. and Tsimi, C., 2011. NOANET: High-rate GPS Network for Seismology and Geodynamics in Greece. Geophysical Research Abstracts, Vol. 13, EGU2011-4840, 2011, EGU General Assembly 2011.

Ganas, A., Marinou, A, Anastasiou, D., Paradissis, D., Papazissi, K., Tzavaras, P. and Drakatos, G., 2013. GPS-derived estimates of crustal deformation in the central and north Ionian Sea, Greece: 3-yr results from NOANET continuous network data, Journal of Geodynamics, 67, $62-71$.

Jacobshagen, V., 1979. Structure and geotectonic evolution of the Hellenides, Proc. VI Colloq Aegean Region Athens, 1977, IGMR, Athens, 1355-1367.

Karakostas, V., Papadimitriou, E. and Papazachos, C., 2004. Properties of the 2003 Lefkada, Ionian islands, Greece, Earthquake seismic sequence and seismicity triggering, BSSA 94/5:19761981.

Lekkas, E., Danamos, G. and Lozios, S., 2001. Neotectonic structure and neotectonic evolution of Lefkada Island, Bull. Geol. Soc. Greece, XXXIV/1, 157-163.

Louvari, E., Kiratzi, A.A. and Papazachos, B.C., 1999. The CTF and its extension to western Lefkada Island, Tectonophysics, 308, 223-236.

Melgar, D., Crowell, B.W., Geng, J., Allen, R.M., Bock, Y., Riquelme, S., Hill, E.M., Protti, M. and Ganas, A., 2015. Earthquake magnitude calculation without saturation from the scaling of peak ground displacement, Geophys. Res. Lett., 42, doi: 10.1002/2015GL064278.

Papadopoulos, G.A., Karastathis, V.K., Ganas, A., Pavlides, S., Fokaefs, A. and Orfanogiannaki, K., 2003. The Lefkada, Ionian Sea (Greece), shock (Mw 6.2) of 14 August 2003: Evidence for the characteristic earthquake from seismicity and ground failures, Earth Planet. Space, 55, 713-718.

Papathanassiou, G., Pavlides, S. and Ganas, A., 2005. The 2003 Lefkada earthquake: Field observations and preliminary microzonation map based on liquefaction potential index for the town of Lefkada, Engineering Geology, 82(1), 12-31.

Papathanassiou, G., Valkaniotis, S., Ganas, A. and Pavlides, S., 2013. GIS-based statistical analysis of the spatial distribution of earthquake-induced landslides in the island of Lefkada, Ionian Islands, Greece, Landslides, 10(6), 771-783. 
Pavlides, S.B., Papadopoulos, G.A., Ganas, A., Papathanassiou, G., Karastathis, V., Keramydas, D. and Fokaefs, A., 2004. The 14 August 2003 Lefkada (Ionian Sea) Earthquake, 5th International Symposium on Eastern Mediterranean Geology, Thessaloniki, Greece, 14-20 April 2004, Reference T5-34.

Rondoyanni, Th., Sakellariou, M., Baskoutas, J. and Christodoulou, N., 2012. Evaluation of active faulting and earthquake secondary effects in Lefkada Island, Ionian Sea, Greece: an overview, Nat Hazards, 61, 843-860, doi: 10.1007/s11069-011-0080-6.

Sachpazi, M., Hirn, A., Clément, C., Haslinger, F., Laigle, M., Kissling, E., Charvis, P., Hello, Y., Lépine, J.-C., Sapin, M. and Ansorge, J., 2000. Western Hellenic subduction and Cephalonia Transform: local earthquakes and plate transport and strain, Tectonophysics, 319, 301-319.

Valkaniotis, S., Ganas, A., Papathanassiou, G. and Papanikolaou, M., 2014. Field observations of geological effects triggered by the January-February 2014 Cephalonia (Ionian Sea, Greece) earthquakes, Tectonophysics, 630, 150-157. 